\title{
Practical Significance of Teachers' Disciplinary Power and Its Implementation Guarantee
}

\author{
Ran $\mathrm{Li}^{1}$, Shan Jiang ${ }^{1}$, Rong Wei ${ }^{1}$ and Yi Jin ${ }^{1, *}$ \\ ${ }^{I}$ School of Physics and Technology, University of Jinan, Jinan, Shandong 250022, China \\ "Corresponding author. Email: ss_jiny@ujn.edu.cn
}

\begin{abstract}
In 2017, the policy of "Administrative Measures for Primary and Secondary Schools in Qingdao" made by Qingdao city government put forward the term "teacher punishment" for the first time. During the two sessions in 2019, the topic of "teachers' power of punishment" attracted much attention, and the society calls for the return of teachers' power of punishment. Based on this phenomenon, this paper first analyzes the psychology of today's students and teachers, and the relationship between teachers and students. From the perspective of psychology, pedagogy and jurisprudence, this paper expounds the rationality of teachers' disciplinary power, and proposes the work that schools and teachers should do in order to implement teachers' disciplinary power. Finally, combined with the relevant legislation in the United States and the United Kingdom, the significance of the legislation on teachers' disciplinary power in China is illustrated.
\end{abstract}

Keywords: Disciplinary power, implementation guarantee, legislation, case analysis

\section{INTRODUCTION}

In 2017, Qingdao City put forward the word "discipline" in its school management rules, which aroused extensive discussion from all walks of life, and the research on "teacher punishment power" and "educational punishment" has also increased. Scholars have carried out in-depth research on the basis, necessity and implementation system of legislation. However, in the existing laws of China, the term "teacher punishment" has not been explicitly put forward, which has brought great difficulties to the legislation of "teacher punishment power". In foreign countries, educational punishment has long been popular. Although Japan has not clearly proposed the "power of discipline for teachers", it has stipulated the boundary between "corporal punishment" and "discipline"; the United States has adopted a "zero tolerance" policy and has continuously improved and corrected it. The legislation of "Teacher Discipline" in the United Kingdom has gone through a long process and has been revised many times before it has today's more complete implementation system.

In view of all kinds of misconduct of students at present, the society generally calls for the return of "teacher punishment power", the purpose of which is to hope that teachers will shoulder their responsibilities and obligations to standardize the behavior of students. Most scholars also believe that the right of teachers to punish students is a kind of power for teachers to manage students. The legislation of teachers' punishment power can not only urge teachers to strengthen the management of students, in order to help students better adapt to the society and become qualified members of society, but also limit the excessive use of power by teachers and avoid the behavior that has a negative impact on students' physical and mental health. The legislation of teachers' right to punish will have a profound impact on school education in the future. It is not only to add several provisions to the existing laws, but also related to the future talent training of the country and all aspects of society. Based on the above reality, this paper will analyze the necessity and rationality of teachers' punishment power, and briefly puts forward the basic implementation work of teachers, schools and the country.

\section{ANALYSIS OF THE PRESENT SITUATION OF THE PSYCHOLOGY AND RELATIONSHIP BETWEEN TEACHERS AND STUDENTS}

\subsection{Student Psychological Analysis}

Nowadays, most children are only children. They grow up under the "excessive love" of their parents, relatives and friends. Many children have developed an arrogant character. Combined with the author's internship and parttime experience in Jinan ordinary middle school, we found the following main problems: First of all, some students do not recognize the teacher in their heart and think that what the teacher says is a deaf ear. Moreover, because of the development of the network, students' psychology is easily influenced by some negative thoughts and behaviors on the network, and they will disrespect or even despise the teacher. Secondly, because middle school students are in puberty, they have their own opinions and disobey management than in other periods. For teachers who are strict or they don't like, they will have behaviors such as picking up words, making trouble, talking, and not 
handing in homework in class. In similar situations, teachers often adopt traditional practices, such as heart to heart talk after class, hoping to "make friends" with students to solve problems. However, according to the feedback of some teachers, sometimes the effect of this practice is not obvious. At this time, it is particularly important for teachers to "punish" students to supervise students to return to the right track [1].

\subsection{Teacher Psychological Analysis}

For some new teachers, they prefer to become friends with their students. As a result, new teachers are often cautious when dealing with students. When they should properly criticize or stop students' behavior, they are often soft hearted and merciful. Then the students will quickly catch this, and the behavior of disturbing the classroom order, such as not listening to class, talking in class and picking up conversation, will be even more intensified. At the same time, in the case of social progress, teachers' psychology has also undergone great changes. Due to the acceleration of the pace of life, teachers often face the dual pressure of life and psychology, especially in rural lowincome teachers, which is easy to show job burnout and take a "laissez faire" approach to students. Therefore, the establishment and improvement of the implementation system of teachers' disciplinary power also have a very farreaching impact on urging teachers to exercise their disciplinary power and supervising teachers to take a serious and responsible attitude towards students [2].

\subsection{Current Situation of Teacher-Student Relationship}

Through the above psychological analysis of teachers and students, it can be seen that the relationship between teachers and students is very tense in many cases. And because most students are the only children at home, many teachers often have the psychology of not wanting and not daring to manage. The once beautiful slogan of "respecting teachers and valuing education" has been greatly weakened in this era. In recent years, society has been advocating students' protection and privacy respect. But on the other hand, when students disobey the discipline and even have extreme behavior, how can teachers' rights and interests are protected and inviolable, and how can teachers prove that their stopping behavior is within the legal scope? These practical problems need to be solved urgently, which makes the legislation of teachers' disciplinary power particularly important.

\section{NECESSITY AND RATIONALITY OF TEACHERS' DISCIPLINARY POWER LEGISLATION}

Throughout the ages, punishment and reward have been two common means for teachers to teach their disciples. Just because of the different times, the forms of teachers' punishment are also different. Su Shi, a great writer in the Song Dynasty, once said that if students make mistakes and have not corrected after being taught many times, they can be punished. It can be seen that the word "discipline" has always existed in education and teaching, but because the topic is too sensitive, few people put forward "discipline" as a formal term. In March 2017, Qingdao City issued the policy of "Administrative Measures for Primary and Secondary Schools in Qingdao" and first proposed the term "discipline", which is of milestone significance to the legislation of teachers' disciplinary power. In order to protect teachers' normal education and teaching behavior from the pressure of parents and the interference of social public opinion, and limit teachers' excessive punishment, it is very necessary to legislate teachers' disciplinary power. Meanwhile, the legislation of teachers' disciplinary power is very reasonable. It has its reason from the perspective of psychology, pedagogy, ethics and jurisprudence.

\subsection{Objective Necessity}

The topic of educational disciplinary power has always been full of controversy. There are many disputes among parents, media and the public whether to implement appreciation education or disciplinary education. But in fact, the above two are not incompatible. They can combine with each other and complement each other. In today's multicultural society, students are easily brainwashed by various "cultures", such as "Rice-Circle culture" [3]. Under the erosion of this culture, students are easy to form unhealthy values and affect their studies and even life. At this time, the implementation of appreciation education can not separate students from the unhealthy fantasies of various idols, which needs the punishment of teachers. However, when teachers implement punishment, they find that there is no set of gauged and reasonable standards. This "freedom" puts teachers in a dilemma. If the punishment is too heavy, it will be criticized by parents and public opinion; on the contrary, if the punishment is too light, students will not take it as a warning. Therefore, most teachers choose to turn a blind eye. At this time, some people in turn hope that teachers use the disciplinary power to manage students. As a result, the exercise of teachers' disciplinary power has entered an abnormal cycle This contradiction and the extensive expectation of the society show that teachers' disciplinary power urgently needs legislation to clarify the necessity of responsibility division. 


\subsection{Psychological Basis}

Behaviourist Skinner has made a systematic and comprehensive exposition of "reinforcement". He believes that reinforcement after a certain behavior can increase the probability of such behavior. Skinner used the "Skinner Box" to verify his behaviourism view [4]. In the past, people often overemphasized the role of reinforcement, and under the influence of appreciation education, the public often thought that punishment was inhumane and ineffective behavior. Through Skinner's experiment, it can be seen that punishment is the most effective way to quickly correct a student's behavior. In order for students to continue to maintain healthy and positive behavior and correct bad behavior, it is necessary to constantly give students "stimulation" after punishment, so that their positive behavior will be strengthened constantly, and the combination of punishment and strengthening will have a better corrective effect. In teaching, teachers can use the disciplinary power to help students get rid of bad behavior, and then set up target behavior and several small stages between the starting point behavior and target behavior for students, and give praise, reward or other external stimuli in time whenever students complete the goal of one stage. From this, it can be seen that from the perspective of psychology, teachers' disciplinary power has its specific existence significance and function [5].

\subsection{Pedagogical Basis}

From the perspective of pedagogy, some educators strongly support teachers' disciplinary power, and some educators rationally analyze the advantages and disadvantages of teachers' disciplinary power, but most of them have a common understanding that excessive discipline will cause psychological harm to students, while appropriate discipline can help students develop healthily. They believe that the implementation and promotion of teachers' disciplinary power is possible, scientific and necessary. It is well known that education fosters students and makes them qualified members of society in order to better integrate students into social life in the future. After entering the society, students will face a variety of rules and difficulties. If teachers do not manage students and do not adopt effective methods to regulate their behavior, it will not only have irreparable consequences for the future of students, but also cause great misfortune to students' families. The disciplinary power is the guarantee for teachers to manage students reasonably, legally and effectively. In the face of unruly students, teachers should promptly correct the behavior of students and make them a qualified citizen.

\subsection{Legal Basis}

The legislation of teacher's disciplinary power must first clarify what is the "power" of teacher's disciplinary.
Current laws such as the Teacher Law do not explicitly mention the term "Teacher Disciplinary Power". It is only the current presumption based on the Education Law of the People's Republic of China, Teacher Law and other relevant laws and regulations, which brings a lot of challenges to the legislation. At the same time, educators also have their own views on the definition of "teacher punishment". For example, someone puts forward that the upper concept of "educational punishment" is "administrative punishment" and distinguish the concept of "educational punishment" from the concepts related to it. Most people define the right of educational punishment as the management power of teachers, that is, the power exercised by teachers in order to maintain classroom order and standardize the behavior of students. And the teacher's management right is stipulated in the Education Law, that is, teachers have the responsibility of managing students. Therefore, from a legal perspective, the establishment of teacher disciplinary power has a certain legal basis.

On December 23, 2020, the Chinese Ministry of Education formulated and promulgated the Primary and Secondary School Education Disciplinary Rules (for Trial Implementation) (Ministry of Education Order No. 49). The Rules will be implemented on March 1, 2021. For the first time, the Rules provides for educational punishment in the form of departmental regulations, which systematically stipulates the attributes, scope of application, and implementation rules, procedures, measures, and requirements of educational punishment, aiming to bring educational punishment into the track of the rule of law. And also for the first time, the rules defines the concept of educational punishment, which stipulates that educational punishment is "based on the purpose of education, schools and teachers in a prescribed way manage, discipline or correct students who violate regulations, so as to urge students to take warning, understand and correct mistakes".

\section{MEASUREMENTS TO ACHIEVE TEACHERS' DISCIPLINARY POWER}

\subsection{National Level}

From the above analysis, it can be seen that the legislation of teacher punishment right has great social expectation, and educators are also calling for it. This paper proposes that after the Ministry of Education and Qingdao issued relevant policies, other regions should also introduce and improve the relevant policies as soon as possible according to the education situation in the region. In addition to the rules promulgated by the Ministry of Education, the State should also speed up legislation to protect teachers from interference by parents and the media when necessary to punish students for bad behaviour, and to supervise teachers to assume responsibility for educating students and to prevent teachers from neglecting management of students for fear of accountability. 


\subsection{School Level}

When schools set up relevant regulations in accordance with the law, they should follow the following principles to make teachers' discipline more effective and prevent students from affecting their physical and mental health due to punishment. First of all, the first principle is that the disciplinary content setting should comply with the law of students' physical and mental development. In the middle school stage, students are gradually forming their own values, but influenced by their social experience, they often find that they have different values with their parents and teachers, and they are more likely to be affected by their peers. In the process of author's trainee, it is found that the way most teachers make students recognize their mistakes is often verbal criticism, some teachers let the countdown student go on stage to read their own achievement, and even let the poor student apologize to the whole class. This kind of measure not only can not play the incentive function to the student, on the contrary, will make the student dispel the enthusiasm and selfconfidence to the study. Secondly, the purpose of teacher's disciplinary power should be clarified. In the rules of the Ministry of Education, it is clarified that the educational punishment is not "punishment", but a way of education, and it emphasizes the educational attribute of educational punishment. It is a specific way for schools and teachers to exercise their rights of education, management and evaluation.

The rules stresses that the implementation of educational punishment should follow the principles of education, legitimacy and appropriateness, comply with the law of education and pay attention to the effect of nurture, follow the principle of rule of law and be objective and fair. School and teachers should select appropriate measures to adapt to the degree of students' fault. Finally, teachers' disciplinary power should be prevented from being simplified. Teachers used to punish students for running and standing. These methods were not only too simple, but also the effect was often poor. The students didn't have a deep impression. The rules points out that, if necessary, schools and teachers can implement educational punishment when students are disobedient, disrupting order, anomie of behavior, dangerous, or infringing on rights and interests, etc. At the same time, according to the degree, the rules divides educational punishment into general, heavier and serious levels. After the level is divided, the school can give correct punishment according to the seriousness of the circumstances.

\subsection{Teacher Level}

Teachers are often exposed to the mass media and will be under greater pressure as well as the trust of students and the expectations of parents. Teachers' education punishment should have the following characteristics: rationality, measurement, empathy and purposiveness. When the teacher disciplines the students, he should directly point to the students' behavior in violation of the regulations, and should not expand other aspects of the students, or even use offensive words. Maybe the teacher thinks that doing so can impress the students and avoid making the same mistakes in the future. However, middle school students are in adolescence, they tend to pay more attention to their own inner thoughts, and will be "unconvinced" with the control of parents and teachers. Therefore, no matter what kind of punishment teachers impose on students, they must clarify the mistakes to students, point out which rules have been violated, and put forward the target behavior they want students to achieve, so as to be reasonable and not overly extended. After students correct their wrong behavior, teachers should reward them. Only in this way can teachers' behavior have credibility and be trusted by students, so as not to cause students' rebellious psychology. Therefore, rationality is a necessary condition for teachers to make rational use of disciplinary power.

The role of discipline does lie in its deterrent effect on people, but the relationship between teachers and students is not a cold one between law and citizens. For students, teachers are not only mentors, but also friends to promote progress, so the relationship between teachers and students should be warm and harmonious. Teachers punish students for their better development. Only based on this point can students understand the good intentions of teachers and truly respect teachers from the heart. Teachers' transposition thinking and the feelings between teachers and students are the finishing touch of the rational exercise of teachers' disciplinary power. In addition, the teacher's punishment of students should be effective and in line with the target behavior that the teacher initially expects students to achieve. The reason to prevent the simplification of teachers' disciplinary power is to expect teachers to choose appropriate disciplinary methods in order to achieve the corresponding educational purpose. Teachers can help students divide several stages between starting point behavior and target behavior, so that students can gradually approach the target behavior, so as to increase students' acceptability.

\section{FOREIGN EDUCATION DISCIPLINARY ENLIGHTENMENT}

In the United States, "zero tolerance" is well known as an anti-drug policy. Later, this policy was used in schools, and students were expelled or suspended if they had bad behaviour. This kind of policy has received significant management effects, but the minor bad behaviors of students, such as talking back, talking in class, etc., will also cause the students to face the consequences of suspension. And according to statistics, the implementation of this policy has a certain tendency to racial discrimination, and the number of people who suspend classes every year is very large. Although this "zero tolerance" suspension strategy works well, it also brings many adverse effects to students, such as 
educational and economic pressure, academic backwardness and so on. The United States is also improving the situation. The first is the modification of school disciplinary policies. Some schools choose to stop using the suspension policy, and some schools choose to use the suspension policy in the lower grades. Secondly, establish high-quality online teaching. During the suspension of classes, the network will be used to conduct online centralized teaching for suspended students, so that classes will not be suspended.

The establishment of teachers' disciplinary power in Britain has also experienced a long process. In 1989, the education department banned teachers from punishing students. However, with the development of the times, students' psychology has become more and more complicated, and the rigid relationship between teachers and students has brought great difficulties to teaching, so people have called for the return of the right of education punishment. In 2006, the UK enacted a new law. The law adds new content about teachers' disciplinary power, which gives British teachers a legal basis to deal with unruly students. And the law defines the content of teacher punishment, such as teachers have the right to use force in schools to avoid students from hurting themselves or others. In 2014, the United Kingdom further promulgated the Behavior and Discipline in Schools: Recommendations for Principals and Teachers, which further subdivided the content of teachers' disciplinary powers. The document stipulated that teachers should focus on guiding education, and schools must disclose their code of conduct to parents every school year to strive to obtain the approval and support of parents. It also made detailed regulations on the appropriate scope of power. The promulgation of this policy makes teachers' exercise of educational punishment more concise, and also limits teachers' excessive exercise of their disciplinary power to a certain extent. It is a great progress in British educational punishment [6].

From the development process of educational punishment power in Britain and America, it can be seen that the real establishment of educational punishment needs the test of time, and the specific implementation needs to be determined according to the specific situation of domestic students and education. As a developing country, China urgently needs to improve its people's quality and education level to accelerate its national development, and China has a huge population. Based on the above specific situation of China, the "zero tolerance" policy of the United States does not apply to China. On the contrary, the early situation of British legislation is similar to that of our country, and its step-by-step legislation and improvement process are worthy of our reference.

\section{DISCUSSION AND CONCLUSION}

The legislation of teacher punishment power is expected by the public and has great social expectation. It is not only to add several provisions to the existing laws; furthermore, it is related to the training of national talents and all aspects of society. Nowadays, there is a phenomenon of "parents not bearing to control, teachers not daring control", which is very detrimental to the development of young people. Without correct guidance, students will not form correct values and then not be able to become qualified successors. With the increasing voice of calling for the return of teachers' punishment power in society, there are more and more related research. The legislation of teacher punishment power needs time to revise and improve again and again. The society and the education community are both looking forward to the promulgation of it. However, from another perspective, if relevant laws are promulgated in the future, teachers should still make clear that guidance and education should be the main focus in the teaching process, and that the purpose of "discipline" is "abstinence" rather than "punishment".

\section{ACKNOWLEDGMENT}

This work was supported by Group Theory Curriculum Ideological and Political Education Demonstration Project of Shandong Province, Research Project of Postgraduate Education and Teaching Reform in Shandong Province (SDYJG19038) and Quality Course Construction of Colleges and Universities in Shandong Province (JPKC201311).

\section{REFERENCES}

[1] ZHANG Yan-yan, Analysis on the psychological characteristics and causes of middle school students in junior and senior high school, Examination Weekly 2021(53):13-14. (In Chinese)

[2] RAN Hong-ji, Research on the adjustment countermeasures of junior middle school teachers' mental health problems, New Curriculum 2020(23):214-215. (In Chinese)

[3] LAI Li-hui, The Negative Influence of "Fan-circle" Culture on College Students and its Countermeasures, Journal of Tianjin Sino-German University of Applied Sciences 2021(03):110-113. (In Chinese)

[4] YANG Li-jun, Thoughts on the necessity of legislation of teachers' disciplinary power, Education Science Forum 2019(11):8-9. (In Chinese)

[5] ZHENG Qiao, Application of Skinner's reinforcement learning theory in Education, Journal of Seeking Knowledge Guide 2015(06):64. (In Chinese)

[6] LI Chao-heng, ZHANG Hong, A new probe into the legislation of teachers' disciplinary power in China -Based on the new regulations on the management of teachers' disciplinary power in Britain and the United States, Education Exploration 2015(11):149-152. (In Chinese) 